\title{
Attitudes of the Students at the Institutes of Fine Arts in Iraq Towards Implementing Active Learning Strategies in Arabic Language Courses and the Associated Challenges
}

\author{
Dr. Abed Muhsen Hamad Al-Amery \\ Assistant professor \\ The Institute of Fine Arts for Males and Females/ Evening Classes in Al-Karkh, Baghdad, Iraq
}

\begin{abstract}
The present study aimed to explore the attitudes of the students at the institutes of fine arts in Iraq towards implementing active learning strategies in Arabic language courses. It aimed to explore the associated challenges. A descriptive analytical approach was adopted. A purposive sampling method was used. The sample was selected from two institutes of fine arts in Al-Karkh, Baghdad, Iraq. To be specific, the researcher selected 125 male students from the Institute of Fine Arts for Males/ Morning Classes in Al-Karkh. He also selected 110 female students from the Institute of Fine Arts for Females/ Morning Classes in Al-Karkh. Questionnaire forms were distributed to those students. All these forms were retrieved and considered valid for analysis. SPSS program was used. It was found that respondents have positive attitudes towards implementing active learning strategies in Arabic language courses at the institutes of fine arts in Iraq. It was found that AL strategies shall improve the respondents' reading, writing, speaking and listening skills. However, it was found that AL strategies don't provide students with equal chances in terms of participating in the lesson. It was found that implementing such strategies is difficult in the classrooms including a great number of students.
\end{abstract}

Keywords: Attitude, active learning strategies, Arabic language, challenges

DOI: $10.7176 / \mathrm{JEP} / 11-13-08$

Publication date:May $31^{\text {st }} 2020$

\section{Introduction}

Learning isn't about memorizing information, and facts only. In fact, it is a mental process which requires having students involved in this process. During the learning process, the students' emotions and intellect shall be engaged to acquire new knowledge, gain experiences and develop skills. Such skills may include: spiritual, social, cognitive and motor skills. The acquired knowledge shall be internalized and manifest through actions and behaviors (Lubis et al., 2009).

Several theories about learning were developed. For instance, the constructivist learning theory was developed to analyze and examine the learning process. It suggests that each person acquires new knowledge through discovering things by himself/herself (Norton, 2010). It is developed by Jean Piaget. It suggests that each learner constructs his/her own schema based on the information presented to him/her. It suggests that one learns through observing things and people in the surrounding environment and interacting with it. Through such observation and interaction, one shall add the acquired information to the schema of prior knowledge to reach the new knowledge. This theory suggests that learners learn differently because their prior experiences of learners differ from one learner to another. Therefore, learners perceive things and conceptualize concepts differently. In simple words, this theory suggests that knowledge is constructed based on the prior knowledge existing in one's mind (Alanazi, 2016).

In this regard, in order for the learner to learn effectively, he must search for information by himself/herself and understand it well. A learner must also discover things by himself/herself and exert effort to solve problems. $\mathrm{He} / \mathrm{she}$ must also exert effort to come up with new ideas. In fact, he/she must strive for obtaining knowledge and learn new concepts. That shall make the acquired knowledge and concepts deeply rooted within the learner's minds (Chai et al., 2011). Therefore, instructors are advised to refrain from deliver knowledge students through the direct instructional approach. Instead, students should acquire knowledge by themselves. Therefore, instructor should serve only as a facilitator to the acquisition of knowledge through employing effective teaching methods. That can be achieved through letting students discover things by themselves to acquire knowledge (Berring \& Heuvel, 2009).

Due to the significance of engaging students in learning, the term (active learning) emerged. Active learning refers to the process of having the students engaged actively in the learning process and letting them create knowledge by themselves. It aims at developing students' skills and thinking capabilities. Such skills may include: meta-cognitive, problem-solving and analytical thinking skills (Aksit et al., 2016).

Active learning refers to employing strategies that make students "do" things instead of "listening". It aims at turning them into active learners instead of being passive learners. It makes students discover, process and apply information by themselves. It offers students many opportunities to meaningfully talk and listen, read, write, and reflect on ideas, content, issues related to the academic material (Meyers and Jones, 1993:6). It refers to engaging 
students in activities that stimulate their thinking process about what they do. It lets students comment on the results (Bonwell \& Eison, 1991).

Active learning $(\mathrm{AL})$ strategies are implemented in language classroom. They can be used for learning native or foreign languages (Abu Hamdeh and Al-Khawaldeh, 2017 and Momani et al., 2016). They can be implemented for improving students' reading, listening, writing and speaking skills (Echevarria et al., 2003). AL strategies may include: problem solving, role playing, group discussion, brain storming, peer-teaching, cooperative learning, group work, discovery, inquiry, and field trips. They may include letting the student make demonstration or explanation and do homework by himself/herself (Mulatu \& Bezabih (2018).

It has been suggested that students' academic achievement is positively affected by the level of their active participation in the learning process (Gardner et al., 1994). AL strategies improve students' critical thinking and communicative skills (Demirci, 2017). They improve students' communication with their peers and make the language learning process easier. They attract students to the language learning process and make them interested in learning language. They make students perceive the language being learnt as comprehensible (Kamarulzaman et al., 2018). They develop students' self-confidence, and promote a life-long learning approach. They develop students higher order thinking and leadership skills (Omar et al., 2012; Jamila \& Maslawati, 2017)

Although there are several benefits for active learning strategies, there are several challenges facing the process of implementing them. For instance, these strategies are difficult to implement in the classrooms including a great number of students. They are difficult to implement in the classroom that lack the required audio-visual equipment. They are difficult to implement because they require dedicating much time by teachers for pre-class preparation. Furthermore, teachers can't cover the whole targeted material when implementing these strategies in a regular manner (El-Salhi, 2013). In the light of the aforementioned information, the researcher aimed to explore the attitudes of the students at the institutes of fine arts in Iraq towards implementing active learning strategies in Arabic language courses and the associated challenges.

\section{The study's Objectives}

The present study aimed to:

1)- Identify the attitudes of the students enrolled at the institutes of fine arts in Iraq towards implementing active learning strategies in Arabic language courses

2)- Identify the challenges hindering the process of implementing active learning strategies in Arabic language courses at the institutes of fine arts in Iraq

\section{The study's Questions}

The present study aimed to answer the following questions:

Q.1. What are the attitudes of the students enrolled at the institutes of fine arts in Iraq towards implementing active learning strategies in Arabic language courses?

Q.2. What are the challenges hindering the process of implementing active learning strategies in Arabic language courses at the institutes of fine arts in Iraq?

\section{The study's Significance}

The present study is significant due to the following reasons:

-There aren't many studies that shed a light on the implementation of AL strategies at the institutes of fine arts in Iraq. Thus, this study fills a gap in the relevant literature.

-This study enriches the knowledge of the Arabic language instructors at the institutes of fine arts in Iraq about the teaching methods and students' willingness to implement AL strategies at classroom. Thus, this study improves the quality of Arabic language education at these institutes

-This study provides decision makers at the Iraqi Ministry of Education with knowledge about the effectiveness of active learning strategies in teaching Arabic language courses. That shall enable those decision makers to make decisions that improve the quality of Arabic language education at the aforementioned institutes.

\section{Limits of the Study}

-Temporal limits: The present study was conducted during the first semester of the academic year of 2019/2020

-Spatial limits: The present study was conducted in two institutes of fine arts in Al-Karkh, Baghdad, Iraq. These institutes are: the Institute of Fine Arts for Males/ Morning Classes in Al-Karkh \& the Institute of Fine Arts for Females/ Morning Classes in Al-Karkh.

-Human limits: The present study targets the students enrolled at the institutes of fine arts in Iraq.

\section{Definitions:}

\subsection{Theoretical definition:}

-Active learning: It refers to the process of having the students engaged actively in the learning process and letting 
them create knowledge by themselves. It aims at developing students' skills and thinking capabilities (Aksit et al., 2016).

-Attitude: It refers to an evaluative judgment that indicates the degree to which someone prefers a thing or a person (Crano and Prislin, 2006, p.347).

\subsection{Operational definition:}

-Active learning: It refers to the implementation of active learning strategies in Arabic language courses at the institutes of fine arts in Iraq. These strategies include: problem solving, role playing, group discussion, brain storming, peer-teaching, cooperative learning, group work, discovery, inquiry, field trips and letting the student make demonstration or explanation and do homework by himself/herself

-Attitudes: They refer to the attitudes of the students enrolled at the institutes of fine arts in Iraq towards implementing active learning strategies in Arabic language courses.

\section{Theoretical framework}

\subsection{Active learning}

Through active learning, students shall be engaged actively in the learning process. AL strategies improve students' critical thinking skills. They make students engaged actively in the process of building ideas, and facts and developing their skills. They improve students' retention of information and promote a better understanding for information. That is because AL strategies let students apply knowledge, solve problems, work in groups, and do group assignments. AL strategies make students interested in the course, especially when using role playing, games and etc.. (Kishore, 2017).

It should be noted that students remember $10 \%$ of the information they read and $20 \%$ of the information they hear. Students remember $30 \%$ of the information they see and $50 \%$ of the information they see and hear. However, students remember $90 \%$ of the things they do and the information they apply! Therefore, letting students apply knowledge through AL strategies shall improve students' retention of information and concepts. In addition, letting students know that the things they have learnt can be applied in the real world shall motivate them to learn more information (Kishore, 2017).

AL strategies involve carrying out goal-directed activities that let students search for information by themselves. They shall enable instructors to identify the gaps in the students' existent knowledge. They shall enable instructors to identify the skills that the students must develop. They shall motivate students to learn (Saylor and Ganea, 2018).

\subsection{Challenges hindering the implementation of active learning (AL) strategies}

There are several challenges hindering the implementation of AL strategies. Such challenges may include: a need for recruiting creative and innovative teachers. They include: the need to dedicate much time by teachers for preclass preparation (Miller, and Metz, 2014). They include: the lack of the needed instructional material and the insufficient time of the lecture (Momani et al., 2016)

Such challenges may include: students' resistance to this type of learning strategies. Such resistance is usually shown by the students are don't accept change and the students who are used to passive learning strategies (i.e. direct instruction method). In addition, implementing the active learning strategies in a regular manner shall hinder the instructor from covering the whole academic material (Kishore, 2017)

In addition, in case the active learning strategies are implemented in the classrooms including a great number of students, some students shall not be engaged in the learning process. Thus, active learning strategies are not effective in such classrooms. Furthermore, when conducting brainstorming activity, some students may fear expressing their ideas or feel shy to do that. Thus, AL strategies may not be effective for teaching shy students (Kishore, 2017). Implementing such strategies increase the teachers' workload, and some AL activities require much time by students to do (Mulatu \& Bezabih, 2018).

\section{Review of Empirical Literature}

Momani et al. (2016) aimed to explore the attitudes of EFL Saudi teachers in Tabuk, KSA towards implementing active learning strategies in English language courses. The sample consists from 35 teachers. A two-part questionnaire was used for data collection. It was found that respondents have positive attitudes towards these strategies. In addition, these strategies improve students' communication with teachers and motivate students to learn. They provide students with access to academic material and references. They improve students' retention and recall of grammatical rules. They promote collaboration in classroom. They encourage students to express their opinions. They improve students' language skills (i.e. writing, reading, listening and speaking). They provide them with opportunities to practice language. They make students interested in the course and promote positive attitudes towards it.

Mei et al. (2017) aimed to explore the attitudes of lecturers towards implementing active learning strategies 
for teaching Arabic language courses to non-native speakers. The sample consists from 10 lecturers who teach Arabic language courses to non-native speakers at Sultan Idris Education University in Malaysia. A questionnaire was used for collecting data. It was found that cooperative learning strategies play an effective role in improving language skills (listening, reading, speaking and writing). Such strategies promotes autonomy among learners in the learning process. They facilitate the process of understanding information. They increase the social interaction in the lecture hall. They improve the learning experiences of students.

Abu Hamdeh and Al-Khawaldeh (2017) aimed to explore the effectiveness of implementing active learning strategies for developing the Arabic language reading and writing skills of third grade students in Jordan. An experimental approach was adopted. The sample consists from 70 female and male third grade students. Those students were divided into experimental and control groups. Pre-tests and post-tests were used for assessing the respondents' reading and writing skills. It was found that the active learning strategies play an effective role in improving the reading and writing skills of third grade students

Mulatu \& Bezabih (2018) aimed to explore the EFL teachers' attitudes towards active learning strategies in English language courses. The sample consists from 12 teachers and 60 students selected from secondary schools at Dawuro, Southern Nations, at Ethiopia. Data was collected from teachers through a questionnaire and form students through filling an observation checklist. Quantitative and qualitative approach were adopted. It was found that active learning strategies improve the quality of education. Such strategies enhance students' understanding of information and improve students' relationship with one another. They make students active learners and improve their self-confidence. They promote autonomy among learners in the learning process and offer students' more opportunities to practice language. They shall make students handle the responsibility of their own learning.

Kamarulzaman et al. (2018) aimed to explore the impact of active learning strategies on students' attitudes towards learning English language. A questionnaire was used. The sample consists from 100 students who were selected during the academic year (2017/2018). Those students were selected from Teknologi Petronas University in Malaysia. It was found that students' attitudes are positive in this regard. Employing these strategies develop students' higher-order thinking skills. It provides students with equal chances in terms of participating in the lesson. It encourages students to participate and engage in the lesson. It serves as an interesting way for learning language. It promotes a better understanding for information. It improve students' retention of information.

\section{Methodology}

9.1. Approach

A descriptive analytical approach was adopted. This approach is adopted by scholars to offer a sensory description for things. It may be adopted for exploring variables (Lawless and Heymann, 1999).

\subsection{Data Collection Methods}

The researcher collected two types of data:

-Primary data. It refers to the data collected through the questionnaire

-Secondary data. It refers to the data collected through reviewing the relevant empirical and theoretical studies, and books.

\subsection{Population and sample}

The population consists from all the students who are enrolled at the institutes of fine arts in Iraq. A purposive sampling method was used. The sample was selected from two institutes of fine arts in Al-Karkh, Baghdad, Iraq. To be specific, the researcher selected 125 male students from the Institute of Fine Arts for Males/ Morning Classes in Al-Karkh. He also selected 110 female students from the Institute of Fine Arts for Females/ Morning Classes in Al-Karkh. Questionnaire forms were distributed to those students. All these forms were retrieved and considered valid for analysis. The response rate is $100 \%$. Information about the sample is presented below:

Table (1): Distribution of the sample in accordance with gender

\begin{tabular}{|l|l|l|l|}
\hline Variable & Category & Frequency & Percentage \\
\hline \multirow{2}{*}{ Gender } & Male & 125 & 53.191 \\
\cline { 2 - 4 } & Female & 110 & 46.800 \\
\hline
\end{tabular}

$\mathrm{N}=235$

$53.19 \%$ of the respondents are males and $46.80 \%$ of the respondents are females. 
Table (2): Distribution of the respondents in the Institute of Fine Arts for Males/ Morning Classes in Al-Karkh in accordance with the department

\begin{tabular}{|l|l|l|l|}
\hline Variable & Category & Frequency & Percentage \\
\hline \multirow{5}{*}{ Department } & Plastic art department & 25 & 20 \\
\cline { 2 - 4 } & Audio-visual art department & 20 & 16 \\
\cline { 2 - 4 } & Design department & 20 & 16 \\
\cline { 2 - 4 } & Arabic calligraphy and decoration department & 20 & 16 \\
\cline { 2 - 4 } & Theater department & 20 & 16 \\
\cline { 2 - 4 } & Music department & 20 & 16 \\
\hline
\end{tabular}

$20 \%$ of the respondents in the latter institute are enrolled in the plastic art department and $16 \%$ of the respondents in the latter institute are enrolled in the audio-visual art department. $16 \%$ of the respondents in the latter institute are enrolled in the design department. $16 \%$ of the respondents in the latter institute are enrolled in the Arabic calligraphy and decoration department. $16 \%$ of the respondents in the latter institute are enrolled in the theater department. 16\% of the respondents in the latter institute are enrolled in the music department.

Table (3): Distribution of the respondents in the Institute of Fine Arts for Females/ Morning Classes in Al-Karkh in accordance with the department

\begin{tabular}{|l|l|l|l|}
\hline Variable & Category & Frequency & Percentage \\
\hline \multirow{5}{*}{ Department } & Plastic art department & 25 & 22.72 \\
\cline { 2 - 4 } & Audio-visual art department & 17 & 15.454 \\
\cline { 2 - 4 } & Design department & 17 & 15.454 \\
\cline { 2 - 4 } & Arabic calligraphy and decoration department & 17 & 15.454 \\
\cline { 2 - 4 } & Theater department & 17 & 15.454 \\
\cline { 2 - 4 } & Music department & 17 & 15.454 \\
\hline
\end{tabular}

$22.72 \%$ of the respondents in the latter institute are enrolled in the plastic art department and $15.45 \%$ of the respondents in the latter institute are enrolled in the audio-visual art department. $15.45 \%$ of the respondents in the latter institute are enrolled in the design department. $15.45 \%$ of the respondents in the latter institute are enrolled in the Arabic calligraphy and decoration department. $15.45 \%$ of the respondents in the latter institute are enrolled in the theater department. $15.45 \%$ of the respondents in the latter institute are enrolled in the music department.

\subsection{Instrument}

The researcher used a five point Likert questionnaire to collect data. This questionnaire consists from a cover page and three main parts. The cover pages identifies the goals of the questionnaire. It identifies the operational definition of the term (active learning). It suggests that the collected information shall remain confidential. The first part collects information about the department that the respondents are enrolled at. The second part collects data about the attitudes of respondents towards implementing active learning strategies in Arabic language courses. It was developed based on the following works: Kamarulzaman et al. (2018), Kishore (2017), Mulatu \& Bezabih (2018), Saylor and Ganea (2018), Mei et al. (2017), and Gardner et al. (1994). The third part collects data about the challenges hindering such implementation. It was developed based on the following works: Mulatu \& Bezabih (2018), El-Salhi (2013), Momani et al. (2016), Kishore (2017) and Momani et al. (2016).

\subsection{Validity of the instrument}

The validity of the instrument was measured through passing the initial form of the questionnaire to two faculty members specialized in teaching methods. Those instructors work at Iraqi universities and have much expertise. They were asked to assess this form in terms of clarity, language, and relevancy. They suggested that the questionnaire is clear and free from any language mistake. They suggested that the items are related to the study's goals. However, one of the faculty members recommended deleting two items. Thus, the researcher deleted these items.

\subsection{Reliability of the instrument}

Cronbach alpha coefficient value was calculated by the researcher. This value is 0.842 . That means that the questionnaire offers readers reliable and accurate results.

\subsection{Statistical analysis and criteria}

To analyze the obtained data, the researcher used SPSS program and calculated standard deviations and means. He calculated frequencies and percentages. He calculated Cronbach alpha coefficient. For classifying means, specific criteria were adopted by the researcher. These criteria are presented through table 4 . 
Table (4): The criteria that are used by the researcher for classifying means

\begin{tabular}{|l|l|l|}
\hline Range & Level & Attitude \\
\hline 2.33 or less & Low & Negative attitude \\
\hline $2.34-3.66$ & Moderate & Neutral attitude \\
\hline 3.67 or more & High & Positive attitude \\
\hline
\end{tabular}

Regarding the five point Likert scale, it consists from five (5) rating categories. Those categories are displayed through the table below. Each category represents a specific score.

Table (5): The categories and scores of the five point Likert scale

\begin{tabular}{|l|l|l|l|l|l|}
\hline Category & Strongly agree & Agree & Neutral & Disagree & Strongly disagree \\
\hline The score it represents & 5 & 4 & 3 & 2 & 1 \\
\hline
\end{tabular}

\section{Discussion and Results:}

\subsection{Discussion and Results Related to the first question:}

Q.1. What are the attitudes of the students enrolled at the institutes of fine arts in Iraq towards implementing active learning strategies in Arabic language courses?

Table (6) presents the results related to the first question

Table (6): Respondents' attitudes towards active learning strategies in Arabic language courses

\begin{tabular}{|c|c|c|c|c|c|}
\hline No. & Statement & Mean & Std. & Attitude & Level \\
\hline & \multicolumn{5}{|c|}{ Implementing active learning strategies in Arabic language courses } \\
\hline 1. & improves the Arabic reading skills & 4.94 & 0.34 & Positive & High \\
\hline 2. & improves the Arabic writing skills & 4.86 & 0.52 & Positive & High \\
\hline 3. & improves the Arabic listening skills & 4.75 & 0.64 & Positive & High \\
\hline 4. & improves the Arabic speaking skills & 4.73 & 0.97 & Positive & High \\
\hline 5. & develops students' higher-order thinking skills & 4.81 & 0.18 & Positive & High \\
\hline 6. & $\begin{array}{l}\text { provides students with equal chances in terms of } \\
\text { participating in the lesson }\end{array}$ & 2.14 & 0.22 & Negative & Low \\
\hline 7. & increase students' interest in these courses & 4.52 & 0.50 & Positive & High \\
\hline 8. & $\begin{array}{l}\text { improves students' retention of Arabic language- } \\
\text { related information }\end{array}$ & 4.63 & 0.63 & Positive & High \\
\hline 9. & $\begin{array}{l}\text { promotes a better understanding for Arabic language- } \\
\text { related information }\end{array}$ & 4.35 & 0.28 & Positive & High \\
\hline 10. & improves students' self-confidence & 2.04 & 0.91 & Negative & Low \\
\hline 11. & Improves the students' relationship with one another & 4.51 & 0.27 & Positive & High \\
\hline 12. & improves students' academic achievement & 4.34 & 0.63 & Positive & High \\
\hline 13. & improves the learning experiences of students & 4.60 & 0.78 & Positive & High \\
\hline 14. & $\begin{array}{l}\text { enables instructors to identify the gaps in the students' } \\
\text { existent knowledge }\end{array}$ & 1.98 & 0.42 & Negative & Low \\
\hline & Total & 4.08 & 0.52 & Positive & High \\
\hline
\end{tabular}

It was found that respondents have positive attitudes towards implementing active learning strategies in Arabic language courses. That is because the overall mean is 4.08. It was found that AL strategies shall improve the respondents' reading, writing, speaking and listening skills. That is because the means of statements 1, 2, 3, and 4 are: $4.94,4.86,4.75$, and 4.73 respectively. It was found that AL strategies develop students' higher-order thinking skills, because the relevant mean is 4.81 . The latter result is consistent with the result concluded by Kamarulzaman et al. (2018). It may be attributed to the nature of AL activities which stimulate students to propose ideas, solve problems, make decisions and think in a critical manner. That participates in improving students' higher-order thinking skills.

It was found that AL strategies don't provide students with equal chances in terms of participating in the lesson, because the relevant mean is 2.14. The latter result is inconsistent with the result concluded by Kamarulzaman et al. (2018). It may be attributed to the fact that some AL activities don't ensure that all students shall participate in the lesson. It was found that AL strategies increase students' interest in Arabic language courses because the relevant mean is 4.52. The latter result is consistent with what's suggested by Kishore (2017). It may be attributed to the fact that some AL activities which make students enjoy the learning process. Such activities include: games that may require using grammatical rules.

It was found that AL strategies improve the students' retention of Arabic language-related information, because the relevant mean is 4.63. The latter result is consistent with the result concluded by Kamarulzaman et al. (2018). It may be attributed to the fact that students retrain the information they apply by themselves. It was found that AL strategies promote a better understanding for Arabic language-related information because the relevant mean is 4.35 . The latter result is consistent with the result concluded by Mulatu \& Bezabih (2018). It was found 
that AL strategies don't improve students' self-confidence because the relevant mean is 2.04. The latter result is inconsistent with the result concluded by Mulatu \& Bezabih (2018). It may be attributed to the fact that implementing AL strategies in the classrooms including a great number of students shall not provide all students with chances to speak. Thus, students with low self-confidence may not obtain a chance to speak and engage in the lesson.

It was found that AL strategies improve students' relationship with one another, because the relevant mean is 4.51. The latter result is consistent with the result concluded by Mulatu \& Bezabih (2018). It may be attributed to the fact that some AL strategies include carrying out group works that require cooperation. That shall increase the interaction between students and improve their relationships with each other. It was found that AL strategies improve students' academic achievement, because the relevant mean is 4.34 . The latter result is consistent with what's suggested by Gardner et al. (1994).

It was found that AL strategies improve the learning experiences of students, because the relevant mean is 4.60. The latter result is consistent with the result concluded by Mei et al. (2017). It was found that AL strategies don't enable instructors to identify the gaps in the students' existent knowledge because the relevant mean is 1.98. The latter result is inconsistent with what's suggested by Saylor and Ganea (2018). It may be attributed to the fact that implementing AL strategies in the classrooms including a great number of students shall not provide all students with chances to speak or engage in the lessin. Thus, it shall be difficult for the instructor to identify the gaps in the student's existent knowledge, if he/she didn't speak or engage in the lesson.

\subsection{Discussion and Results Related to the second question:}

Q.2. What are the challenges hindering the process of implementing active learning strategies in Arabic language courses at the institutes of fine arts in Iraq?

The results of related to the second question are presented through table 7 .

Table (7): The challenges hindering the process of implementing active learning strategies

\begin{tabular}{|c|l|c|c|c|c|}
\hline No. & Statement & Mean & \multicolumn{2}{|c|}{ Std. } & \multicolumn{2}{|c|}{ Attitude } & Level \\
\hline & Implementing active learning strategies in Arabic language courses & 4.72 & 0.74 & Positive & High \\
\hline 1. & $\begin{array}{l}\text { isn't suitable for teaching shy students } \\
\text { is difficult because it requires carrying out much pre-class } \\
\text { preparation by the instructor }\end{array}$ & 4.83 & 0.32 & Positive & High \\
\hline 3. & $\begin{array}{l}\text { is difficult because the duration of the lecture isn't enough } \\
\text { is difficult in the classrooms including a great number of } \\
\text { students }\end{array}$ & 4.56 & 0.19 & Positive & High \\
\hline 4. & $\begin{array}{l}\text { in a regular manner is difficult because it hinders instructors } \\
\text { from covering the whole academic material }\end{array}$ & 4.91 & 0.34 & Positive & High \\
\hline 5. & $\begin{array}{l}\text { is difficult because it requires recruiting instructors who are } \\
\text { creative and innovative }\end{array}$ & 4.43 & 0.27 & Positive & High \\
\hline & \multicolumn{1}{|c|}{ Total } & 4.53 & 0.39 & Positive & High \\
\hline
\end{tabular}

It was found that the severity of the challenges hindering the process of implementing active learning strategies in Arabic language courses at the institutes of fine arts in Iraq is high. That is because the total mean is 4.53. It was found that implementing active learning strategies in Arabic language courses isn't suitable for teaching shy students, because the relevant mean is 4.72 . The latter result is consistent with the result concluded by Mulatu \& Bezabih (2018). It may be attributed to the fact that some AL activities require speaking before the whole class which is considered difficult for shy students.

It was found that such implementation is difficult because it requires carrying out much pre-class preparation by the instructor, because the relevant mean is 4.83. The latter result is consistent with the result concluded by ElSalhi (2013). It was found that such implementation is difficult because the duration of the lecture isn't enough. That's because the relevant mean is 4.56. The latter result is consistent with the result concluded by Momani et al. (2016). It was found that such implementation is difficult in the classrooms including a great number of students, because the relevant mean is 3.78. The latter result is inconsistent with the result concluded by El-Salhi (2013).

It was found that implementation such strategies in a regular manner is difficult because it hinders instructors from covering the whole academic material, because the relevant mean is 4.91 . The latter result is consistent with the result suggested by Kishore (2017). It was found that such implementation is difficult because it requires recruiting instructors who are creative and innovative, because the relevant mean is 4.43 . The latter result is consistent with the result concluded by Momani et al. (2016).Finding such teachers is difficult.

\section{Conclusion}

It was found that respondents have positive attitudes towards implementing active learning strategies in Arabic language courses at the institutes of fine arts in Iraq.. Such strategies improve students' retention of Arabic 
language-related information and increase students' interest in these courses. They develop students' higher-order thinking skills. They promote a better understanding for Arabic language-related information and improve the learning experiences of students. However, it was found that AL strategies don't provide students with equal chances in terms of participating in the lesson. Such strategies don't improve students' self-confidence.

The severity of the challenges hindering the process of implementing active learning strategies in Arabic language courses at the institutes of fine arts in Iraq is high. Such challenges include: the inadequate duration of the lecture and the need to carry out much pre-class preparation by the instructor. In addition, such strategies aren't suitable for teaching shy students.

\section{Recommendations}

The researcher recommends:

- $\quad$ Providing all classes at the institutes of fine arts in Iraq with all the ICT equipment that instructors may need for implementing AL strategies.

- Providing instructors at the institutes of fine arts in Iraq with training courses about active learning strategies and activities.

- Making adjustments to the curricula of Arabic language courses at the institutes of fine arts in Iraq in order to for instructor to employ active learning strategies.

- Conducting other studies about the effectiveness of implementing AL strategies for teaching art courses at the institutes of fine arts in Iraq.

\section{References}

Abu Hamdeh, S.s and Al-Khawaldeh, N. (2017). The impact of active learning on developing the reading and writing skills of third grade students in Jordan. Al-Mushkelah Journal for Human and Social Sciences. 4(2), p.129-169 https://www.wise.edu.jo/sites/default/files/filefield_paths/5_1.pdf

Aksit, F., Niemi, H., \& Nevgi, A. (2016). Why is active learning so difficult to implement: The Turkish case, Australian Journal of Teacher Education, 41(4).

Alanazi, A. (2016). A critical review of constructivist theory and the emergence of constructionism. American Research Journal of Humanities and Social Sciences. Vol.2

Berring, R. C. \& Heuvel, K. V. (2009). Teaching advanced legal research: philosophy and context. Legal Reference Services Quarterly, 28 (1-2),

Bonwell, C, \& James, A. (1991): Active learning: creating excitement in the classroom. Washington. USA. Washington University Press.

Chai, C. S., Wong, B. \& Teo, T. (2011). Singaporean pre-service teachers' beliefs about epistemology, teaching and learning, and technology. Teacher Development: An international journal of teachers' professional development, 15 (4), 485-498.

Crano, W. D., \& Prislin, R. (2006). Attitudes and persuasion. Annual Review of Psychology, Vol. 57, 345 - 374

Miller, C. and Metz, M. (2014). A comparison of professional-leval faculty and student perceptions of active learning: its current use, effectiveness and barriers. Advances in Psychology Education, 38(3), p.246 - 252

Demirci, C. (2017). The effect of active learning approach on attitudes of 7 th grade students. International Journal of Instruction, 10(4), 129-144

El-Salhi, S. (2013). The effectiveness of using a program based on active learning strategies on fourth graders' English performance in Gaza UNRWA Schools. MA thesis. The Islamic University - Gaza. Gaza.

Echevarria, J., M.E. Vogt, and D. Short. (2003). Making content comprehensible for English language learners, $2^{\text {nd }}$ edition. Boston. USA. Allyn and Bacon.

Gardner, R., Heward, W. L. \& Grossi, T. A. (1994). Effects of response cards on student participation and academic achievement: A systematic replication with inner-city students during whole-class science instruction', Journal of Applied Behavior Analysis 27(1): 63-71

Jamila, S. \& Maslawati, M. (2017). Identifying the effectiveness of active learning strategies and benefits in curriculum and pedagogy course for undergraduate TESL students. Creative Education, 2312 - 2324

Kishore, N. (2017). An introduction to active learning strategies. $1^{\text {st }}$ edition. India. Education Publishing

Kamarulzaman, L.; Abdul Ghani, M.; and Wan Daud, W. (2018). The effect of active learning strategies on students' attitudes towards English: A study at Universiti Teknologi Petronas. Online Journal of Language, Communication, and Humanities. 1(2), 1-8

Lawless H.T., and Heymann H. (1999). Descriptive analysis. In: sensory evaluation of food. Food science text series. Boston. Springer.

Lubis, M. A., Embi, M. A., Yunus, M. M., Wekke, I. S., \& Nordin, N. M. (2009). The application of multicultural education and applying ICT on pesantren in south sulawesi, Indonesia. WSEAS Transactions on Information Science and Applications, 6 (8), 1401-1411.

Mei, S.; Ju, S.; and Mohd, A. (2017). Cooperative learning strategy in teaching Arabic for non native speakers. 
European Journal of Social Sciences Education and Research. 11(2), p.262-267.

Meyers, C. \&Thomas B. Jones, (1993). Promoting active learning: Strategies at the college classroom. San Francisco, Jossey-Bass Publishers.

Momani, M.; Asiri, M.; and Alatawi, S. (2016). The impact of implementing active learning strategies in teaching English from the perspective of Tabuk educational region intermediate school teachers. Asian Journal of Educational Research. 4(1). 19-35

Mulatu, M., \& Bezabih, W. (2018). Perceptions and practices of EFL teachers in implementing active learning in English classes: the case of three selected secondary schools in Dawro zone, SNNPRS, Ethiopia. International Journal of Education, 10(2), 88-94.

Norton, L., Aiyegbayo, O., Harrington, K., Elander, J., \& Reddy, P. (2010). New lecturers' beliefs about learning, teaching and assessment in higher education: the role of the PGCLTHE programme. Innovations in Education and Teaching International, 47 (4), 345-356.

Omar, A., Taib, N. F., \& Basri, I. D. (2012). Project-Based Learning: English Carnival in Universiti Kuala Lumpur-Malaysia France Institute. The English Teacher, 27 - 41.

Saylor, M and Ganea, P. (2018). Active learning from infancy to childhood: social motivation, cognition, and linguistic mechanism. Springer. Switzerland. 